\title{
A systematic review of neo-adjuvant radiotherapy in the treatment of breast cancer
}

\author{
Muneer Ahmed ${ }^{1}$, Felix Jozsa ${ }^{1}$ and Michael Douek ${ }^{2}$ \\ ${ }_{1}^{1}$ Division of Surgery and interventional Science, University College London, Royal Free Hospital, 9th Floor (East), 2QG, 10 Pond St, London NW3 2PS, UK \\ ${ }^{2}$ Nuffield Department of Surgical Sciences, University of Oxford, Botnar Research Centre, Windmill Road, Oxford OX3 7LD, UK
}

\section{Abstract}

Introduction: The use of neo-adjuvant radiotherapy (NRT) has been proven effective at improving cancer related outcome measures, including overall-survival (OS) in the management of solid cancers. However, its utilisation in breast cancer has not been explored to the extent of neo-adjuvant chemotherapy (NAC). The evidence for the application of NRT in breast cancer is evaluated.

Methods: PubMed, Embase and the Cochrane Library databases were searched systematically in August 2020 for studies that addressed the role of NRT in the treatment of breast cancer. Studies were deemed eligible if they reported on objective outcome measurements of OS, disease free-survival (DFS) or pathological complete response (pCR) and attained a satisfactory quality assessment.

Findings: A total of 23 studies reported upon 3,766 patients who had received NRT of which 3,233 also received NAC concurrently (neo-adjuvant chemo-radiotherapy (NCRT)). The pCR values ranged from $14 \%$ to $42 \%, 5$-year DFS $61.4 \%$ to $81 \%$ and 5 -year OS $71.6 \%$ to $84.2 \%$. Complications were confined to radiation dermatitis with no cases of implant loss reported during breast reconstruction. The application of NRCT alone showed no significant difference in OS or DFS compared to NCRT followed by surgery.

Interpretation: Numbers of patients receiving exclusively NRT is small. However, NCRT is oncologically safe with a low side-effect profile including preceding breast reconstruction. Potential benefits include precise cancer volume targeting, chemosensitisation, elimination of delays in adjuvant therapies and alternatives to chemotherapy in oestrogen receptor positive patients. These factors warrant further exploration within randomised controlled-trials.

Keywords: neo-adjuvant, radiotherapy, breast cancer, chemo-radiotherapy

\section{Introduction}

The application of both neo-adjuvant and adjuvant therapies in surgical oncology has resulted in a $20 \%$ increase in 5-year survival across a range of visceral malignancies over the last 40 years [1]. Adjuvant radiotherapy (RT) utilisation in breast cancer has increased by $29 \%$ since 1973 [1] but the role of neo-adjuvant radiotherapy (NRT) has to date been
Correspondence to: Muneer Ahmed Email: muneer.ahmed@kcl.ac.uk

ecancer 2021, 15:1175

https://doi.org/10.3332/ecancer.2021.1175

Published: $22 / 01 / 2021$

Received: 30/05/2020

Publication costs for this article were supported by ecancer (UK Charity number 1176307).

Copyright: (c) the authors; licensee ecancermedicalscience. This is an Open Access article distributed under the terms of the Creative Commons Attribution License (http:// creativecommons.org/licenses/by/3.0), which permits unrestricted use, distribution, and reproduction in any medium, provided the original work is properly cited. 
poorly explored. This is despite its extensive clinical application within rectal cancer, in which it has been demonstrated to significantly reduce local recurrence compared to adjuvant RT or surgery alone and improve overall survival (OS) compared to surgery alone [2]. The tumouricidal effects of combining neo-adjuvant radiotherapy and chemotherapy in rectal cancer have also led to a decrease in tumour size, stage of nodal disease and less adverse histological features (lymphovascular invasion and tumour differentiation) [3]. These findings have supported combining neo-adjuvant radiotherapy and chemotherapy in rectal cancer [4]. The enhancement of chemotherapy, avoidance of delay to RT and precise targeting of the cancer in situ are all potential benefits of the NRT approach. There is also the future potential to allow for the combining pharmacological interventions with ionising radiation, which more specifically target tumour tissue [5]. The current evidence for the use of NRT as an alternative approach to the management of breast cancer is appraised within this systematic review.

\section{Methods}

\section{Study selection}

A systematic review of the literature was performed using PubMed, Embase and the Cochrane Library databases to identify all original articles published up to August 2020 that evaluated the role of NRT in the management of breast cancer. The search terms used were: Neoadjuvant radiotherapy AND breast cancer. Studies were restricted to those conducted upon humans and published in the English language. The related articles function was used to broaden the search, and all abstracts, studies and citations obtained were reviewed. References of the acquired articles were also searched by hand. The last search was conducted on 27 August 2020.

\section{Inclusion criteria}

Studies were included if they fulfilled the following eligibility criteria: performance of NRT in primary breast cancer; recorded objective outcome measures in terms of OS, disease free-survival (DFS) or pathological complete response ( $p C R$ ); attained a satisfactory quality assessment (at least 5 of 7); and were written in the English language.

\section{Exclusion criteria}

Studies that failed to fulfil the inclusion criteria and those in which the outcomes of interest were not reported were excluded. Other exclusion criteria were: full text not available; review article; letter to the editor; editorial report; case report; duplicate publication; published abstracts and articles not in the English language.

\section{Data extraction}

Data were extracted from the selected studies using a data extraction form, which included information on: publication details; study design; number of patients; neo-adjuvant therapy and protocol; type of surgery; adjuvant treatment protocol; follow-up; number of patients achieving pCR; number of local and metastatic recurrences; DFS and OS and complications. The quality of randomised controlled trials (RCTs) was assessed using the 'risk of bias' tool from the Cochrane Handbook [6] and cohort studies according to the Strengthening the Reporting of Observational Studies in Epidemiology (STROBE) recommendations [7] and seven items of the STROBE statement were considered relevant for quality evaluation. Two reviewers extracted data from included studies independently. Comparison of the data extraction and quality score was undertaken, and discrepancies were resolved by consensus.

\section{Statistical analysis}

All extracted data were tabulated and presented as means and percentages. Numerators and denominators were provided to address outcomes of included studies. 


\section{Results}

Following the search and screening of published articles (Figure 1), the detailed literature search resulted in 23 studies being critically appraised for this review (Table 1) [8-28].

\section{Study characteristics}

The studies were published between 1994 and 2017 (Table 1). One study was a RCT [23], another cohort-controlled study [22] and the remainder cohort series [8-21] [24-28]. Overall, the studies reported upon 3,766 patients who received NRT, of these only 533 received it alone in three studies $[12,21,23]$ with the remaining 18 studies involving patients being treated sequentially with NAC followed by RT. Five studies reported on the use of breast reconstruction, all of which involved pre-operative combination radio and chemotherapy [15, 16 , $25,27]$. The NRT protocols administered a radiation dose between 45 and $60 \mathrm{~Gy}$ to the whole breast and draining lymph nodes (axillary and extra-axillary including supraclavicular fossa (SCF) and internal mammary nodes (IMNs)) and a boost of between 10 and 15 Gy to the tumour bed. A single study performed targeted volume NRT to the tumour with a total dose of $9.6 \mathrm{~Gy}$ [20]. NAC consisted of anthracyclines alone or combined with taxanes and one study using taxanes alone [8]. One study used neo-adjuvant endocrine therapy [17] and another alkylating agent only [23]. Definitive surgery was conducted between 3 and 8 weeks after completion of neo-adjuvant therapies, with breast reconstruction being conducted in five studies [15, 16, 25, 27]. Adjuvant treatments were stated as administered to patients in all trials except two involving breast reconstruction [27, 28]. Follow-up time periods were stated in 12 trials [8, 11, 12, 16-18, 20, 21, 23, 25-28] and ranged between a median value of 14-384 months.

\section{Study quality}

The risk bias tool for the single included RCT is demonstrated in Table 2a. The RCT lacked a power analysis and details regarding blinding of personnel and participants but was overall considered of acceptable quality. The relevant items of the STROBE statement were used for the quality assessment of included cohort studies are shown in Table $2 \mathrm{~b}$. The overall STROBE score ranged between 5 and 7 . The methodology and reported data of all included studies were considered adequate.

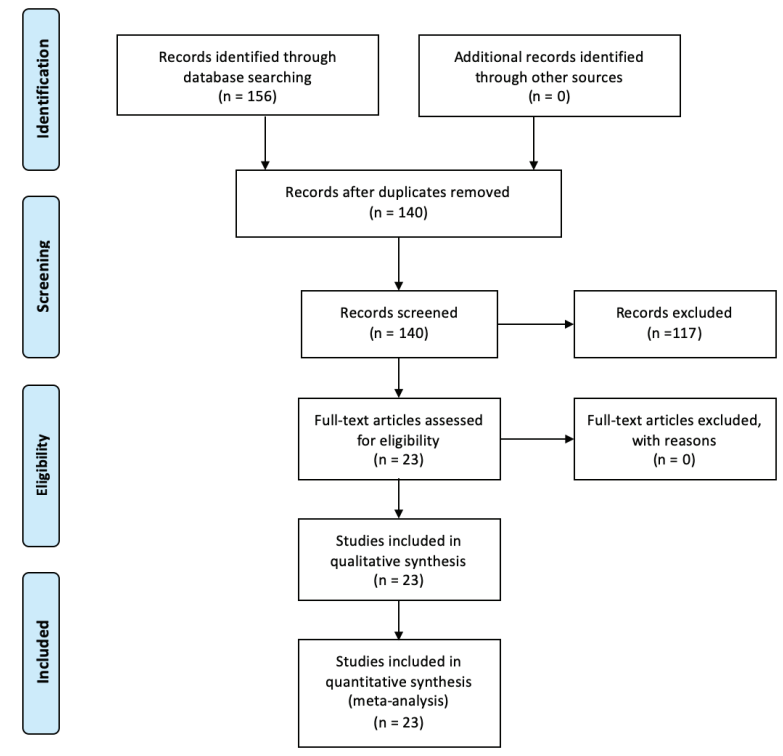

Figure 1. PRISMA flow diagram. 
Table 1. Characteristics of included studies.

(a) Involving preoperative RT and CT

\begin{tabular}{|c|c|c|c|c|c|c|c|c|c|}
\hline \multirow[t]{2}{*}{$\begin{array}{l}\text { Study and } \\
\text { type }\end{array}$} & \multirow[t]{2}{*}{$\begin{array}{l}\text { Total no. } \\
\text { of pts }\end{array}$} & \multicolumn{2}{|c|}{$\begin{array}{c}\text { Neo-adjuvant } \\
\text { therapy }\end{array}$} & \multicolumn{2}{|c|}{ Neo-adjuvant protocol } & \multirow{2}{*}{$\begin{array}{l}\text { Surgery } \\
\text { (BCS versus } \\
\mathrm{Mx}) \text { and } \\
\text { timingß }\end{array}$} & \multicolumn{2}{|c|}{ Adjuvant treatment protocol } & \multirow{2}{*}{$\begin{array}{l}\text { Median } \\
\text { follow-up } \\
\text { (months) }\end{array}$} \\
\hline & & RT & NAC & RT & NAC & & RT & $A C$ & \\
\hline $\begin{array}{l}\text { Touboul } \\
\text { et al [26] }\end{array}$ & $\begin{array}{l}97 \\
(\text { IIIA-IV) }\end{array}$ & 97 & 97 & $\begin{array}{l}\text { Whole breast, } \\
\text { chest wall, } \\
\text { regional lymph } \\
\text { nodes irradiated } \\
\text { (total } 45 \text { Gy in } \\
23 \text { fractions), } 3 \\
\text { weeks after NAC }\end{array}$ & $\begin{array}{l}\text { Doxorubicin day } 1 \text { (45 } \\
\left.\mathrm{mg} / \mathrm{m}^{2}\right) \text { plus vincristine } \\
\text { day } 2\left(1.5 \mathrm{mg} / \mathrm{m}^{2}\right) \text { plus } \\
5 \text {-fluorouracil }(500 \mathrm{mg} / \\
\left.\mathrm{m}^{2}\right) \text { and cyclophospha- } \\
\text { mide }\left(300 \mathrm{mg} / \mathrm{m}^{2}\right) \text { day } \\
2,3,4 . \text { Four cycles, } \\
\text { repeated every } 28 \text { days }\end{array}$ & $\begin{array}{l}27: 37 \\
\text { no surgery } \\
(n=33) \\
4 \text { weeks } \\
\text { after NAC }\end{array}$ & $\begin{array}{l}30 \text { Gy boost in } \\
15 \text { fractions in } \\
\text { those patients } \\
\text { whose primary } \\
\text { tumour had } \\
\text { disappeared } \\
(n=33)\end{array}$ & $\begin{array}{l}\text { Anthracycline } \\
\left(30 \mathrm{mg} / \mathrm{m}^{2}\right)\end{array}$ & 93 \\
\hline $\begin{array}{l}\text { Colleoni } \\
\text { et al [13] }\end{array}$ & $\begin{array}{l}32(\mathrm{~T} 2- \\
\mathrm{T} 4)\end{array}$ & 29 & 32 & $\begin{array}{l}\text { Whole breast } \\
\text { irradiation ( } 50 \mathrm{~Gy} \text { ) } \\
\text { and boost to tu- } \\
\text { mour nodule ( } 10 \\
\text { Gy), 3-4 weeks } \\
\text { following NAC }\end{array}$ & $\begin{array}{l}\text { Doxorubicin }\left(60 \mathrm{mg} / \mathrm{m}^{2}\right) \\
\text { and cyclophosphamide } \\
\left(600 \mathrm{mg} / \mathrm{m}^{2}\right) \text { for three } \\
\text { courses } 21 \text { days apart }\end{array}$ & $\begin{array}{l}25: 7 \\
\text { ANC per- } \\
\text { formed in } \\
\text { all patients }\end{array}$ & NA & NA & NA \\
\hline $\begin{array}{l}\text { Skinner } \\
\text { et al [33] }\end{array}$ & $\begin{array}{l}36 \\
(\text { IIB-IV) }\end{array}$ & 30 & 30 & $\begin{array}{l}\text { Total } 50 \text { Gy in } 25 \\
\text { fractions, begin- } \\
\text { ning on day } 15 \text { of } \\
5 \text {-FU, }\end{array}$ & $\begin{array}{l}\text { 5-flurouracil ( } 200 \mathrm{mg} / \\
\left.\mathrm{m}^{2}\right) \text { for eight consecu- } \\
\text { tive weeks }\end{array}$ & $\begin{array}{l}\text { All patients } \\
\text { received } \\
\text { mastec- } \\
\text { tomy } \\
\text { within 4-6 } \\
\text { weeks }\end{array}$ & NA & $\begin{array}{l}\text { Adriamycin }(n=28) \\
\text { tamoxifen }(n=2)\end{array}$ & $22(8-40)$ \\
\hline $\begin{array}{l}\text { Lerouge } \\
\text { et al [18] }\end{array}$ & $\begin{array}{l}120 \\
\text { (IIIA- } \\
\text { IIIC) }\end{array}$ & 120 & 120 & $\begin{array}{l}\text { Whole breast and } \\
\text { regional lymph } \\
\text { nodes ( } 45 \text { Gy in } \\
23 \text { fractions over } \\
31 \text { days), } 3 \text { weeks } \\
\text { after the fourth } \\
\text { cycle of NAC }\end{array}$ & $\begin{array}{l}\text { Four cycles of either } \\
\text { doxorubicin day } 1 \text { ( } 45 \\
\left.\mathrm{mg} / \mathrm{m}^{2}\right) \text { plus vincristine } \\
\text { day } 2\left(1.5 \mathrm{mg} / \mathrm{m}^{2}\right) \text { plus } \\
5 \text {-fluorouracil }(500 \mathrm{mg} / \\
\left.\mathrm{m}^{2}\right) \text { and cyclophos- } \\
\text { phamide }\left(300 \mathrm{mg} / \mathrm{m}^{2}\right) \\
\text { day } 2,3,4(\mathrm{n}=94) ; \text { or } \\
\text { theprubicin day } 1 \text { (40 } \\
\left.\mathrm{mg} / \mathrm{m}^{2}\right) \text { plus vindesine } \\
\text { day } 2\left(2 \mathrm{mg} / \mathrm{m}^{2}\right) \text { plus } \\
5 \text {-fluorouracil }(500 \mathrm{mg} / \\
\left.\mathrm{m}^{2}\right) \text { and cyclophospha- } \\
\text { mide }\left(300 \mathrm{mg} / \mathrm{m}^{2}\right) \text { day } \\
2,3,4 \text { and } 5(n=16) . \\
\text { Cycles repeated every } \\
21 \text { days. } \\
4 \text { weeks after RT, a fifth } \\
\text { cycle of CT was given }\end{array}$ & $\begin{array}{l}71: 49 \\
8 \text { weeks } \\
\text { following } \\
\text { completion } \\
\text { of RT }\end{array}$ & NA & $\begin{array}{l}\text { vincristine (1.5 } \\
\left.\mathrm{mg} / \mathrm{m}^{2}\right) \text { on Day } 1 \text {; } \\
5 \text {-fluorouracil } \\
500 \mathrm{mg} / \mathrm{m}^{2} \text { ) and } \\
\text { cyclophosphamide } \\
300 \mathrm{mg} / \mathrm{m} \text { i.v. on } \\
\text { Days } \\
2,3 \text { and } 4 \text { ( } n=94) \text {. } \\
\text { Or } 6 \text { monthly cycles } \\
\text { of } \\
\text { vinorelbine ( } 25 \mathrm{mg} / \\
\left.\mathrm{m}^{2}\right) \text { on Days } 1 \text { and } 5 \text {, } \\
5-\text { fluorouracil } \\
\left(350 \mathrm{mg} / \mathrm{m}^{2}\right) \text { from } \\
\text { Day } 1 \text { to Day } 5 \text {, and } \\
\text { leucovorin } 250 \\
\left(\mathrm{mg} / \mathrm{m}^{2}\right) \text { on Days } 2 \\
\text { and } 4(n=26)\end{array}$ & 140 \\
\hline
\end{tabular}


Table 1. (a) Involving preoperative RT and CT (Continued)

\begin{tabular}{|c|c|c|c|c|c|c|c|c|c|}
\hline $\begin{array}{l}\text { Chakravar- } \\
\text { thy et al } \\
{[34]}\end{array}$ & $\begin{array}{l}34 \\
\text { (IIA-IIIB) }\end{array}$ & 30 & 34 & $\begin{array}{l}\text { Whole breast } \\
\text { (total } 4,680 \mathrm{cGy} \\
\text { in } 28 \text { fractions) } \\
\text { and regional } \\
\text { nodes irradiated } \\
\text { (total } 4,500 \mathrm{cGy} \\
\text { in } 25 \text { fractions) }\end{array}$ & $\begin{array}{l}\text { Paclitaxel }\left(175 \mathrm{mg} / \mathrm{m}^{2}\right) \\
\text { every } 3 \text { weeks for three } \\
\text { cycles, followed by } \\
\text { paclitaxel }\left(30 \mathrm{mg} / \mathrm{m}^{2}\right) \\
\text { twice-weekly }\end{array}$ & $\begin{array}{l}\text { 16:21 } \\
\text { 3-4 weeks } \\
\text { following } \\
\text { completion } \\
\text { of RT }\end{array}$ & NA & $\begin{array}{l}\text { Four cycles of doxo- } \\
\text { rubicin/cyclophos- } \\
\text { phamide }(n=28)\end{array}$ & $23(1-46)$ \\
\hline $\begin{array}{l}\text { Shanta } \\
\text { et al [24] }\end{array}$ & $\begin{array}{l}1,117 \\
\text { (IIB-IIIB) }\end{array}$ & 1,117 & 1,117 & $\begin{array}{l}\text { Tumour dose (to- } \\
\text { tal } 4,000 \text { cGy in } \\
20 \text { fractions), and } \\
\text { additional dose to } \\
\text { posterior axillary } \\
\text { fields } \\
\text { RT began on day } \\
2 \text { following start } \\
\text { of NAC }\end{array}$ & $\begin{array}{l}\text { Two regimens (not } \\
\text { randomised) } \\
\text { 1. Cyclophosphamide } \\
\left(600 \mathrm{mg} / \mathrm{m}^{2}\right), 5 \text {-fluo- } \\
\text { rouracil }\left(600 \mathrm{mg} / \mathrm{m}^{2}\right) \\
\text { and methotrexate }(40 \\
\left.\mathrm{mg} / \mathrm{m}^{2}\right) .(n=954) 2 . \\
\text { Cyclophosphamide } \\
\left(600 \mathrm{mg} / \mathrm{m}^{2}\right), 5 \text {-fluoro- } \\
\text { uracil }\left(600 \mathrm{mg} / \mathrm{m}^{2}\right) \text { and } \\
\text { adriamycin }\left(75 \mathrm{mg} / \mathrm{m}^{2}\right) \\
\text { or epirubicin }(90 \mathrm{mg} / \\
\left.\mathrm{m}^{2}\right) .(n=163) \\
\text { Both regimens } \\
\text { given three courses at } \\
\text { 3-weekly intervals }\end{array}$ & $\begin{array}{l}\text { NS 'usually } \\
\text { mastecto- } \\
\text { my' } \\
3 \text { weeks } \\
\text { after NAC }\end{array}$ & $\begin{array}{l}\text { Internal mam- } \\
\text { mary RT (total } \\
4,000 \text { cGy in } \\
20 \text { fractions) }\end{array}$ & $\begin{array}{l}\text { All patients given } \\
\text { 4th CT cycle 8-12 } \\
\text { days postoperatively }\end{array}$ & $\begin{array}{l}\text { NS } \\
\text { (varied) }\end{array}$ \\
\hline $\begin{array}{l}\text { Alvarado- } \\
\text { Miranda } \\
\text { et al }-[9] \\
\text { Cohort } \\
\text { series }\end{array}$ & $\begin{array}{l}112 \\
\text { (IIB-IIIB) }\end{array}$ & 112 & 112 & $\begin{array}{l}\text { Whole breast and } \\
\text { nodal areas fol- } \\
\text { lowing NAC; } 60 \\
\text { Gy divided into } \\
50 \text { Gy in } 5 \text { weeks } \\
\text { plus boost } 10 \\
\text { Gy in } 1 \text { week to } \\
\text { palpable disease }\end{array}$ & 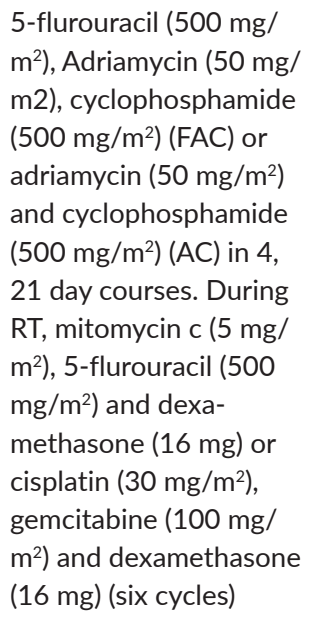 & $\begin{array}{l}\text { 6-8 weeks; } \\
(0: 112) \\
\text { (ANC per- } \\
\text { formed in } \\
\text { all patients) }\end{array}$ & NA & $\begin{array}{l}\text { FAC or AC; two } \\
\text { additional courses } \\
\text { and endocrine ther- } \\
\text { apy if ER positive }\end{array}$ & $43^{h}$ \\
\hline $\begin{array}{l}\text { Adams } \\
\text { et al [8] } \\
\text { Cohort } \\
\text { series }\end{array}$ & $\begin{array}{l}105 \\
(\text { (IIB-IIIC) }\end{array}$ & 105 & 105 & $\begin{array}{l}\text { Breast, axillary } \\
\text { and SCF nodes } \\
\text { (weeks } 2-7 \text { ), } 1.8 \\
\text { Gy per fraction } \\
\text { to total dose of } \\
45 \text { Gy + boost } \\
\text { of } 14 \text { Gy at } 2 \text { Gy } \\
\text { per fraction to } \\
\text { originally palpable } \\
\text { tumour. }\end{array}$ & $\begin{array}{l}30 \mathrm{mg} / \mathrm{m}^{2} \text { paclitaxel bd, } \\
10-12 \text { weeks. } \\
\text { Trastuzumab }(2 \mathrm{mg} / \mathrm{kg}) \\
\text { if HER-2 positive }\end{array}$ & $\begin{array}{l}4 \text { weeks } \\
\text { (all patients } \\
\text { received } \\
\text { ANC) }\end{array}$ & NA & $\begin{array}{l}\text { Combination } \\
\text { chemotherapy and } \\
\text { endocrine therapy } \\
\text { (ER positive) }\end{array}$ & 60 \\
\hline
\end{tabular}


Table 1. (a) Involving preoperative RT and CT (Continued)

\begin{tabular}{|c|c|c|c|c|c|c|c|c|c|}
\hline $\begin{array}{l}\text { Roth } \\
\text { et al [22] } \\
\text { Cohort- } \\
\text { controlled } \\
\text { series }\end{array}$ & $\begin{array}{c}644^{\mathrm{C}} \\
(\mathrm{IIA}-\mathrm{IIIC})\end{array}$ & 315 & 315 & $\begin{array}{l}50 \text { Gy whole } \\
\text { breast and SCF, } 5 \\
\times 2 \text { Gy/week }\end{array}$ & $\begin{array}{l}\text { Epirubicin and cyclo- } \\
\text { phospham-ide (four } \\
\text { cycles) or adriamycin } \\
\text { and cyclophospham- } \\
\text { ide (four cycles) or } \\
\text { cyclophospham-ide, } \\
\text { methotrexate, 5-fluo- } \\
\text { rouracil (three or six } \\
\text { cycles) or epirubicin } \\
\text { and cyclophospham-ide } \\
\text { (six cycles) }\end{array}$ & $(160: 155)$ & $\begin{array}{l}50 \text { Gy plus } 10 \\
\text { Gy boost in } \\
\text { BCS }^{c}\end{array}$ & $\begin{array}{l}\text { As NAC but with } \\
\text { taxane regime also } \\
\text { included }^{c} \\
\text { Endocrine therapy if } \\
\text { ER positive }\end{array}$ & NS \\
\hline $\begin{array}{l}\text { Daveau } \\
\text { et al [14] } \\
\text { Cohort } \\
\text { controlled } \\
\text { series }\end{array}$ & $\begin{array}{c}165 \\
(T 2-3 \leq \\
7 \mathrm{~cm})\end{array}$ & 165 & 165 & $\begin{array}{l}\text { Whole breast } \\
\text { and loco-regional } \\
\text { nodal areas, } 45 \\
\text { Gy + boost of } \\
10-15 \text { Gy }\end{array}$ & $\begin{array}{l}\text { Adriamycin ( } 25 \mathrm{mg} / \\
\left.\mathrm{m}^{2}\right) \text {, cyclophospham- } \\
\text { ide }\left(500 \mathrm{mg} / \mathrm{m}^{2}\right) \text { and } \\
5 \text {-fluorouracil }(500 \mathrm{mg} / \\
\left.\mathrm{m}^{2}\right) \text { or docetaxel }(75 \\
\left.\mathrm{mg} / \mathrm{m}^{2}\right) \text { and Adriamycin } \\
\left(50 \mathrm{mg} / \mathrm{m}^{2}\right) ; 4 \text { weekly } \\
\text { for six cycles }\end{array}$ & $\begin{array}{l}65^{\mathrm{a}}(53: 12) \\
\text { (ANC in all } \\
\text { patients) }\end{array}$ & NA & $\begin{array}{l}\text { Endocrine therapy } \\
\text { for ER positive } \\
\text { patients. } \\
\text { Chemo-therapy } \\
\text { for heavy axillary } \\
\text { involvement }\end{array}$ & NS \\
\hline $\begin{array}{l}\text { Bollet } \\
\text { et al [11] }\end{array}$ & $\begin{array}{c}59 \\
(\mathrm{~T} 2-3)\end{array}$ & 59 & 59 & $\begin{array}{l}\text { Whole breast } \\
\text { irradiation to } 50 \\
\text { Gy in } 5 \text { weeks. } \\
\text { Internal mammary } \\
\text { chain and supra/ } \\
\text { infra-clavicular } \\
\text { nodes irradiated } \\
\text { to } 46 \text { Gt in } 4.6 \\
\text { weeks }\end{array}$ & $\begin{array}{l}5 \text {-flurouracil ( } 500 \\
\mathrm{mg} / \mathrm{m}^{2} / \mathrm{d} \text { ) over five } \\
\text { consecutive days, and } \\
\text { vinorelbine }(25 \mathrm{mg} / \\
\left.\mathrm{m}^{2}\right) \text { on day } 1 \text { and } 6 . \\
\text { Repeated every } 3 \\
\text { weeks for a total of four } \\
\text { courses }\end{array}$ & $\begin{array}{l}41: 18 \\
\text { Minimum } 6 \\
\text { weeks } \\
\text { ANC per- } \\
\text { formed in } \\
\text { all patients }\end{array}$ & $\begin{array}{l}\text { RT boost in } \\
\text { young patients } \\
\text { or margins at } \\
\text { risk }(n=37)\end{array}$ & $\begin{array}{l}\text { None }(n=7) \text {, or } \\
5 \text {-FU, epirubicin } \\
\text { and cyclophospha- } \\
\text { mide in absence of } \\
\text { complete pathologi- } \\
\text { cal response }(n=10) \\
\text { and/or hormone } \\
\text { therapy where } \\
\text { indicated (hormone } \\
\text { therapy alone } n= \\
12, \text { hormone and } \\
\text { chemotherapy } n \\
=30 \text { ) }\end{array}$ & $\begin{array}{c}84 \\
(60-96)\end{array}$ \\
\hline $\begin{array}{l}\text { Ishitobi } \\
\text { et al [17] } \\
\text { Cohort } \\
\text { series }\end{array}$ & $\begin{array}{c}25 \\
(\mathrm{~T} \geq \\
3 \mathrm{~cm} \\
\mathrm{NO}-2)\end{array}$ & 25 & $25^{\mathrm{b}}$ & $\begin{array}{l}50 \text { Gy in } 25 \text { frac- } \\
\text { tions to breast } \\
\text { and SCF (if node } \\
\text { positive) }\end{array}$ & $\begin{array}{l}\text { Anastrazole } 1 \mathrm{mg} / \text { day } \\
\text { for } 24 \text { weeks }\end{array}$ & $\begin{array}{l}25(25: 0) \\
\text { and ANC or } \\
\text { SNB }\end{array}$ & NA & $\begin{array}{l}\text { Adjuvant anastra- } \\
\text { zole (all patients); } \\
\text { trastuzamab if } \\
\text { HER-2 positive and } \\
\text { chemo-therapy } \\
\text { selectively }\end{array}$ & $\begin{array}{c}14 \\
(14-29)\end{array}$ \\
\hline $\begin{array}{l}\text { Matuschek } \\
\text { et al [19] } \\
\text { Cohort } \\
\text { series }\end{array}$ & $\begin{array}{c}315 \\
\text { (T1-T4/ } \\
\text { N0-N1) }\end{array}$ & 315 & 315 & $\begin{array}{l}50 \text { Gy whole } \\
\text { breast and SCF, } 5 \\
\times 2 \text { Gy/week }\end{array}$ & $\begin{array}{l}\text { Epirubicin and cyclo- } \\
\text { phosphamide (four cy- } \\
\text { cles) or adriamycin and } \\
\text { cyclophosphamide (four } \\
\text { cycles) or cyclophos- } \\
\text { phamide, methotrexate, } \\
5 \text {-fluorouracil (four } \\
\text { cycles) or epirubicin } \\
\text { and cyclophospha-mide } \\
\text { (six cycles) }\end{array}$ & 160:155 & NA & $\begin{array}{l}\text { Endocrine therapy if } \\
\text { ER positive }\end{array}$ & NS \\
\hline
\end{tabular}


Table 1. (a) Involving preoperative RT and CT (Continued)

\begin{tabular}{|c|c|c|c|c|c|c|c|c|c|}
\hline $\begin{array}{l}\text { Nardone } \\
\text { et al [20] } \\
\text { Cohort } \\
\text { series }\end{array}$ & $21^{g}$ & 21 & 21 & $\begin{array}{l}9.6 \text { Gy }(6 \times 21 \text { day } \\
\text { cycles) using a } \\
\text { clinically targeted } \\
\text { volume }\end{array}$ & $\begin{array}{l}\text { Liposomal anthracy- } \\
\text { cline }(50 \mathrm{mg} / \mathrm{mq}) \text { and } \\
\text { docetaxel }(75 \mathrm{mg} / \mathrm{mq} \text { ) } \\
\text { (six cycles) }\end{array}$ & $\begin{array}{l}(18: 3) \\
3 \text { weeks }\end{array}$ & $\begin{array}{l}50.4 \text { Gy to } \\
\text { whole breast } \\
\text { or chest wall }\end{array}$ & $\begin{array}{l}\text { AC and endocrine } \\
\text { therapy if ER posi- } \\
\text { tive }\end{array}$ & 31 \\
\hline $\begin{array}{l}\text { Pazos } \\
\text { et al [28] } \\
\text { Cohort } \\
\text { series }\end{array}$ & $\begin{array}{c}22 \\
(\mathrm{~T} 1-4 / \\
\mathrm{N} 0-2)\end{array}$ & 22 & 22 & $\begin{array}{l}\text { Whole breast and } \\
\text { SCF; } 50.4 \mathrm{~Gy}(5 \times \\
1.8 \mathrm{~Gy} / \text { week) }\end{array}$ & $\begin{array}{l}\text { Epirubicin }(90 \mathrm{mg} / \mathrm{m} 2) \\
\text { and cyclophosphamide } \\
\left(600 \mathrm{mg} / \mathrm{m}^{2}\right) \text { (four } \\
\text { cycles) followed by } \\
\text { paclitaxel }(80 \mathrm{mg} / \mathrm{m} 2) \\
\text { (12 cycles) }\end{array}$ & $\begin{array}{l}(22: 0)^{\mathrm{e}} \\
47 \text { days } \\
(26-162 \\
\text { days })^{\Sigma}\end{array}$ & NA & NS & 30 \\
\hline
\end{tabular}

(b) Involving preoperative RT only

\begin{tabular}{|c|c|c|c|c|c|c|c|c|c|}
\hline \multirow[t]{2}{*}{$\begin{array}{l}\text { Study and } \\
\text { type }\end{array}$} & \multirow[t]{2}{*}{$\begin{array}{l}\text { Total no. } \\
\text { of pts }\end{array}$} & \multicolumn{2}{|c|}{$\begin{array}{l}\text { Neo- } \\
\text { adjuvant } \\
\text { therapy }\end{array}$} & \multicolumn{2}{|c|}{ Neo-adjuvant protocol } & \multirow[t]{2}{*}{$\begin{array}{c}\text { Surgery (BCS versus } M x) \text { and } \\
\text { timing } \beta\end{array}$} & \multicolumn{2}{|c|}{$\begin{array}{l}\text { Adjuvant } \\
\text { treatment } \\
\text { protocol }\end{array}$} & \multirow[t]{2}{*}{$\begin{array}{l}\text { Median } \\
\text { follow-up } \\
\text { (months) }\end{array}$} \\
\hline & & RT & NAC & RT & NAC & & RT & $A C$ & \\
\hline $\begin{array}{l}\text { Semiglazov } \\
\text { et al [23] } \\
\mathrm{RC}\end{array}$ & $\begin{array}{c}271 \\
(I I B-I I I A)\end{array}$ & $271^{d}$ & 137 & $\begin{array}{l}60 \text { Gy, single daily } \\
\text { dose of } 2 \text { Gy; SCF } 40 \\
\text { Gy, single daily dose } \\
\text { of } 2 \mathrm{~Gy}\end{array}$ & $\begin{array}{l}\text { Thiotepa (120 mg total } \\
\text { dose), methotrexate } 40 \\
\mathrm{mg} / \mathrm{m}^{2}, 5 \text {-fluorouracil } \\
500 \mathrm{mg} / \mathrm{m}^{2}, 1-2 \text { cycles }\end{array}$ & $\begin{array}{c}(0: 271) \\
3-4 \text { weeks }\end{array}$ & NA & $\begin{array}{l}4-6 \text { cycles } \\
\text { of } A C\end{array}$ & 53 \\
\hline $\begin{array}{l}\text { Calitchi } \\
\text { et al [12] } \\
\text { Cohort } \\
\text { series }\end{array}$ & $\begin{array}{c}75 \\
(\mathrm{~T} 2-3)\end{array}$ & 75 & 0 & $\begin{array}{l}45 \text { Gy ( } 5 \text { weeks) to } \\
\text { whole breast, lower } \\
\text { axillary nodes (includ- } \\
\text { ing } 15 \text { GY boost to } \\
\text { IMNs) }\end{array}$ & - & $(75: 0)$ & NA & $\begin{array}{l}\text { AC and } \\
\text { endocrine } \\
\text { therapy if } \\
\text { ER positive }\end{array}$ & 120 \\
\hline $\begin{array}{l}\text { Riet et al } \\
{[21]}\end{array}$ & $\begin{array}{c}187 \\
(\mathrm{~T} 2-\mathrm{T} 4)\end{array}$ & 187 & 0 & $\begin{array}{l}\text { Whole breast ir- } \\
\text { radiation, SCF and } \\
\text { axilla (total } 45 \text { Gy in } 18 \\
\text { fractions) }\end{array}$ & - & $\begin{array}{l}\text { All patients received mastec- } \\
\text { tomy plus ANC } \\
\text { At least } 4 \text { weeks following } \\
\text { completion of RT }\end{array}$ & NA & $n=58$ (NS) & $\begin{array}{c}384 \\
(264-420)\end{array}$ \\
\hline
\end{tabular}

(c) Involving preoperative RT and/or CT, with breast reconstruction

\begin{tabular}{|c|c|c|c|c|c|c|c|c|c|}
\hline \multirow[t]{2}{*}{$\begin{array}{l}\text { Study and } \\
\text { type }\end{array}$} & \multirow[t]{2}{*}{$\begin{array}{l}\text { Total no. } \\
\text { of pts }\end{array}$} & \multicolumn{2}{|c|}{$\begin{array}{l}\text { Neo- } \\
\text { adjuvant } \\
\text { therapy }\end{array}$} & \multicolumn{2}{|c|}{ Neo-adjuvant protocol } & \multirow[t]{2}{*}{$\begin{array}{l}\text { Surgery }(B C S \\
\text { versus } M x) \text { and } \\
\text { timing } \beta\end{array}$} & \multicolumn{2}{|c|}{$\begin{array}{l}\text { Adjuvant treatment } \\
\text { protocol }\end{array}$} & \multirow[t]{2}{*}{$\begin{array}{l}\text { Median } \\
\text { follow-up } \\
\text { (months) }\end{array}$} \\
\hline & & RT & NAC & RT & NAC & & RT & $A C$ & \\
\hline \multirow[t]{2}{*}{$\begin{array}{l}\text { Aryus et al } \\
{[10]}\end{array}$} & $\begin{array}{c}55 \\
(I-I V)\end{array}$ & 55 & 55 & $\begin{array}{l}\text { Total } 50 \text { Gy with } \\
\text { boost to tumour }\end{array}$ & $\begin{array}{l}\text { Cyclophosphamide (600 } \\
\left.\mathrm{mg} / \mathrm{m}^{2}\right) \text {, fluorouracil (600 } \\
\left.\mathrm{mg} / \mathrm{m}^{2}\right) \text { and methotrexate } \\
\left(40 \mathrm{mg} / \mathrm{m}^{2}\right) \text {; or cyclophos- } \\
\text { phamide }\left(600 \mathrm{mg} / \mathrm{m}^{2}\right) \text { and } \\
\text { epirubicin }\left(90 \mathrm{mg} / \mathrm{m}^{2}\right)\end{array}$ & $\begin{array}{l}\text { Median } 27 \\
(11-21) \text { weeks } \\
\text { after NAC/RT }\end{array}$ & NS & NS & NS \\
\hline & $\begin{array}{l}\text { Seven pat } \\
\text { reconstru }\end{array}$ & . & $\begin{array}{l}\text { mas } \\
\text { flap }\end{array}$ & $\begin{array}{l}\text { tomy + immedi } \\
\text { ere lost in the c }\end{array}$ & $\begin{array}{l}\text { AM recon (presumed pedi } \\
\text { RT group, but no details gi }\end{array}$ & $\begin{array}{l}\text { d). Twenty-eight } \\
\text { regarding other }\end{array}$ & $\delta^{\prime}$ & $\begin{array}{l}\text { urectom } \\
\text { ations }\end{array}$ & \\
\hline
\end{tabular}


Table 1. (c) Involving preoperative RT and/or CT, with breast reconstruction

\begin{tabular}{|c|c|c|c|c|c|c|c|c|c|}
\hline $\begin{array}{l}\text { Skinner et al } \\
{[25]}\end{array}$ & $\begin{array}{l}27 \\
(I I B-I V)\end{array}$ & 27 & 27 & $\begin{array}{l}\text { Total } 45 \text { Gy }(1.8 \\
\text { Gy/fraction over } 5 \\
\text { weeks) }\end{array}$ & $\begin{array}{l}2 \text { weeks of paclitaxel } 60 \\
\mathrm{mg} / \mathrm{m}^{2} \text {, after completion } \\
\text { of RT }\end{array}$ & $\begin{array}{l}\text { All patients } \\
\text { received mastec- } \\
\text { tomy } \\
\text { Within 4-6 } \\
\text { weeks }\end{array}$ & NA & $\begin{array}{l}\text { Four cycles of } \\
\text { adriamycin-based } \\
\text { polychemothera- } \\
\text { py; 5-year course } \\
\text { of tamoxifen } \\
\text { for ER-positive } \\
\text { patients }\end{array}$ & NS \\
\hline & \multicolumn{9}{|c|}{$\begin{array}{l}\text { Two patients underwent immediate TRAM reconstruction (presumed pedicled, but not stated)-one developed early partial flap failure } \\
\text { requiring revision; the other wound problems and delayed healing }\end{array}$} \\
\hline \multirow[t]{2}{*}{$\begin{array}{l}\text { Gerlach et al } \\
{[15]}\end{array}$} & $\begin{array}{l}134 \\
(I-I V)\end{array}$ & 134 & 134 & $\begin{array}{l}\text { Total } 50 \text { Gy in } 2 \text { Gy } \\
\text { fractions. } \\
\text { Internal mammary } \\
\text { lymph nodes irradi- } \\
\text { ated }(n=9)\end{array}$ & $\begin{array}{l}\text { Epirubicin/cyclophos- } \\
\text { phamide plus cyclophos- } \\
\text { phamide/methotrexate/ } \\
\text { fluorouracil }(n=50) \text {; } \\
\text { Epirubicin/cyclophospha- } \\
\text { mide only ( } n=59) \text {; other } \\
(n=25)\end{array}$ & $\begin{array}{l}74: 60 \\
\text { Median } 8 \text { (4-24) } \\
\text { weeks delay after } \\
\text { NAC/RT }\end{array}$ & NS & NS & NS \\
\hline & \multicolumn{9}{|c|}{$\begin{array}{l}\text { 22/134 underwent mastectomy + immediate TRAM reconstruction (presumed pedicled, but not stated) while 60/134 underwent tu- } \\
\text { mourectomy + LD reconstruction. No details were given regarding surgical complications }\end{array}$} \\
\hline \multirow[t]{2}{*}{ Ho et al [16] } & $\begin{array}{l}30 \\
(\text { IIIA-IIIC) }\end{array}$ & 30 & 30 & $\begin{array}{l}\text { Breast and chest } \\
\text { wall. Total } 50 \mathrm{~Gy} \\
\text { in } 25 \text { fractions ( } n= \\
\text { 18); total } 42.5 \mathrm{~Gy} \\
\text { in } 16 \text { fractions ( } n= \\
\text { 12). Median } 6.25 \mathrm{~Gy} \\
\text { boost dose given to } \\
n=26 \text { patients }\end{array}$ & $\begin{array}{l}\text { Adriamycin and cyclo- } \\
\text { phosphamide }(n=1) \text {; } \\
\text { fluorouracil, Adriamycin, } \\
\text { cyclophosphamide ( } n s= \\
\text { 6); cyclophosphamide, } \\
\text { epirubicin, fluorouracil ( } n \\
=4) ; \text {; Adriamycin and tax- } \\
\text { ane }(n=15) \text {; fluorouracil, } \\
\text { epirubicin, cyclophospha- } \\
\text { mide }(n=2)\end{array}$ & $\begin{array}{l}\text { All patients } \\
\text { received skin- } \\
\text { sparing mastec- } \\
\text { tomy. } \\
\text { Median delay } 6.9 \\
\text { (2.7-12.9) weeks } \\
\text { following RT }\end{array}$ & NA & $\begin{array}{l}\text { Tamoxifen where } \\
\text { indicated }\end{array}$ & $42(12-113)$ \\
\hline & \multicolumn{9}{|c|}{$\begin{array}{l}\text { Pedicled TRAMs }(n=24) \text {, LD flaps }(n=5) \text { and a combination of TRAM and LD flaps }(n=1) \text {. Local complications in } n=11(37 \%) \text { included } \\
\text { mastectomy flap necrosis }(n=3) \text {, partial flap necrosis }(n=1) \text {, fat necrosis }(n=1) \text { and flap fibrosis }(n=1) \text {. Donor site complications were } \\
\text { reported in } 20 \%\end{array}$} \\
\hline $\begin{array}{l}\text { Zinzindohoue } \\
\text { et al }[27] \\
\text { Cohort series }\end{array}$ & $83^{f}$ & 83 & 83 & $\begin{array}{l}50 \text { Gy to breast, } \\
\text { axillary, IMN or SCF } \\
\text { nodes }\end{array}$ & $\begin{array}{l}\text { Anthracyclines and taxane } \\
\text { regimens }\end{array}$ & $\begin{array}{l}(0: 83)^{\mathrm{e}} \\
6-8 \text { weeks }\end{array}$ & NA & NS & 24 \\
\hline & \multicolumn{9}{|c|}{$\begin{array}{l}\text { Reconstruction was performed using autologous LD flap with or without prosthesis. Prostheses were used for IBR in } 32 \text { patients (mean } \\
\text { volume } 256 \pm 73 \mathrm{~mm}^{3} \text { ). Five patients had necrosis, all recovered without revision surgery }\end{array}$} \\
\hline
\end{tabular}

NS, Not stated; NA, Non-applicable; BCS, Breast conserving surgery; Mx, Mastectomy; RT, Radiotherapy; NAC, Neo-adjuvant chemotherapy; ANC, Axillary node clearance; ER, Oestrogen receptor; RCT, Randomised controlled trial; IMNs, Internal mammary nodes; SCF, Supraclavicular fossa; (), breast cancer staging; AC, Adriamycin and cyclophosphamide; FAC, 5-fluorouracil, adriamycin and cyclophosphamide; no., Number; pts, Patients; ß, Timing after completion of neo-adjuvant therapies; $\Sigma$, Median with range

aPatients undergoing surgery after neo-adjuvant RT (reminder treated conservatively)

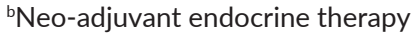

Includes 329 patients in adjuvant only treatment arm

IIncludes patients receiving neo-adjuvant RT + NAC and neo-adjuvant RT alone

eIncludes breast reconstructions

fPatients necessitating mastectomy

glnvasive breast cancer

hMean 
Table 2. Outcomes of included studies.

(a) Involving preoperative RT and CT

\begin{tabular}{|c|c|c|c|c|c|c|c|}
\hline \multirow[t]{2}{*}{ Study } & \multirow{2}{*}{$\begin{array}{l}\text { Number of } \\
\text { patients } \\
\text { achieving } \\
\text { pCR }\end{array}$} & \multirow{2}{*}{$\begin{array}{l}\text { Number of local } \\
\text { recurrences }\end{array}$} & \multirow{2}{*}{$\begin{array}{l}\text { Number of } \\
\text { metastatic } \\
\text { cases }\end{array}$} & \multirow[t]{2}{*}{ DFS (\%) } & \multirow[t]{2}{*}{ OS (\%) } & \multicolumn{2}{|c|}{ Number of complications } \\
\hline & & & & & & Skin-related & Other \\
\hline $\begin{array}{l}\text { Touboul et al } \\
{[26]}\end{array}$ & $\begin{array}{l}\quad 41 \\
\text { (complete } \\
\text { remission) }\end{array}$ & 5 & 5 & $61^{\mathrm{b}}$ & $69^{\mathrm{b}}$ & NS & $\begin{array}{c}\mathrm{N}+\mathrm{V}(n=29) \\
\text { hair loss }(n=90)\end{array}$ \\
\hline $\begin{array}{l}\text { Colleoni et al } \\
{[13]}\end{array}$ & 2 & NS & NS & NS & NS & NS & 5 \\
\hline Skinner et al [33] & 6 & NS & 3 & $\begin{array}{l}83 ; \\
f^{\prime} 27\end{array}$ & NS & 9 & 9 \\
\hline $\begin{array}{l}\text { Lerouge et al } \\
\text { [18] }\end{array}$ & 8 & 11 & 10 & $60^{a}$ & $\mathrm{~g} 66.5$ & NS & NS \\
\hline $\begin{array}{l}\text { Chakravarthy et } \\
\text { al [34] }\end{array}$ & 13 & NS & NS & NS & NS & 1 & 10 \\
\hline Shanta et al [24] & NS & $\begin{array}{l}\text { Local } n=17 ; \\
\text { locoregional } n=16 ; \\
\text { regional only } n=46\end{array}$ & NS & $52.6^{\mathrm{b}} ; 41.4^{\mathrm{c}}$ & $\begin{array}{l}63.9^{\mathrm{b}} \\
58.4^{\mathrm{c}}\end{array}$ & NS & NS \\
\hline $\begin{array}{l}\text { Alvarado- } \\
\text { Miranda et al [9] }\end{array}$ & $47(65)$ & 1 & 4 & $\begin{array}{c}76.9(95 \% \mathrm{Cl} \\
68.2-84.7)\end{array}$ & $\begin{array}{c}84.2(95 \% \mathrm{Cl} \\
75-93)\end{array}$ & 25 & 6 \\
\hline Adams et al [8] & 36 & 5 & 24 & $\begin{array}{c}61.4(95 \% \mathrm{Cl} \\
50.1-70.8)\end{array}$ & $\begin{array}{c}71.6(95 \% \mathrm{Cl}, \\
60.5-80.1)\end{array}$ & NS & NS \\
\hline Roth et al [22] & $116(61)$ & NS & NS & $\begin{array}{c}\text { 68 }- \text { NCRT group } \\
\text { 67.3 }\end{array}$ & $\begin{array}{l}\text { 68.6 }- \text { NCRT group } \\
65^{\mathrm{b}}-\text { Adjuvant group }\end{array}$ & NS & NS \\
\hline $\begin{array}{l}\text { Daveau et al } \\
{[14]}\end{array}$ & $\begin{array}{l}41^{\mathrm{e}}-\text { no } \\
\text { surgery } \\
8\left(19^{\mathrm{e}}\right)- \\
\text { surgery }\end{array}$ & $\begin{array}{l}\text { 32-no surgery } \\
\text { 11-surgery }\end{array}$ & $\begin{array}{c}21(27)^{\mathrm{b}}-\text { no } \\
\text { surgery } \\
14(26)^{\mathrm{b}}-\text { sur- } \\
\text { gery }\end{array}$ & $\begin{array}{c}65(52)^{\mathrm{b}}-\text { no surgery } \\
72(61)^{\mathrm{b}}-\text { surgery }\end{array}$ & $\begin{array}{l}91(77)^{\mathrm{b}}-\text { no surgery } \\
82(79)^{\mathrm{b}}-\text { surgery }\end{array}$ & $\begin{array}{c}\text { 3-no sur- } \\
\text { gery }\end{array}$ & 0 \\
\hline Bollet et al [11] & 16 & 7 & 13 & $83^{a}$ & $88^{a}$ & NS & $\begin{array}{l}\text { Grade } 3(n=4) ; \\
\text { grade } 2(n=16) ; \\
\text { grade } 1(n=18)\end{array}$ \\
\hline $\begin{array}{l}\text { Ishitobi } \\
\text { et al [17] }\end{array}$ & 0 & 1 & 1 & ${ }^{\mathrm{f}} 24$ & g24 & 2 & 1 \\
\hline $\begin{array}{l}\text { Matuschek } \\
\text { et al [19] }\end{array}$ & 116 & NS & NS & NS & NS & NS & NS \\
\hline $\begin{array}{l}\text { Nardone et al } \\
{[20]}\end{array}$ & 3 & 0 & 2 & $19^{* *}$ & $21^{\mathrm{g}}$ & 1 & NS \\
\hline Pazos et al [28] & 5 & 2 & 2 & f18 & $\mathrm{s} 18$ & NS & NS \\
\hline
\end{tabular}


(b) Included studies involving preoperative RT alone

\begin{tabular}{|c|c|c|c|c|c|c|c|}
\hline \multirow[t]{2}{*}{ Study } & \multirow[t]{2}{*}{$\begin{array}{c}\text { Number of patients } \\
\text { achieving pCR }\end{array}$} & \multirow[t]{2}{*}{$\begin{array}{c}\text { Number of local } \\
\text { recurrences }\end{array}$} & \multirow[t]{2}{*}{$\begin{array}{c}\text { Number of meta- } \\
\text { static cases }\end{array}$} & \multirow[t]{2}{*}{ DFS (\%) } & \multirow[t]{2}{*}{ OS (\%) } & \multicolumn{2}{|c|}{$\begin{array}{c}\text { Number of } \\
\text { complications }\end{array}$} \\
\hline & & & & & & Skin-related & Other \\
\hline Semiglazov et al [23] & $\begin{array}{l}\text { 17-NCRT group } \\
\text { 8-NRT group }\end{array}$ & NS & NS & $\begin{array}{l}\text { 81-NCRT group } \\
71.6-N R T \text { group }\end{array}$ & $\begin{array}{c}86.1-\mathrm{NCRT} \text { group } \\
78.3-\mathrm{NRT} \text { group }\end{array}$ & $\begin{array}{l}\text { 9-NCRT } \\
\text { 12-NRT }\end{array}$ & NS \\
\hline Calitchi et al [12] & NS & 9 & 27 & $47^{c}$ & $55^{c}$ & 2 & NS \\
\hline Riet et al [21] & 18 & 15 & NS & $30^{d}$ & $30^{d}$ & 8 & 29 \\
\hline
\end{tabular}

(c) Included studies involving preoperative RT and/or CT, with breast reconstruction

\begin{tabular}{|c|c|c|c|c|c|c|c|}
\hline \multirow[t]{2}{*}{ Study } & \multirow[t]{2}{*}{$\begin{array}{c}\text { Number of patients } \\
\text { achieving } \mathrm{pCR}\end{array}$} & \multirow[t]{2}{*}{$\begin{array}{l}\text { Number of local } \\
\text { recurrences }\end{array}$} & \multirow[t]{2}{*}{$\begin{array}{c}\text { Number of } \\
\text { metastatic cases }\end{array}$} & \multirow[t]{2}{*}{ DFS (\%) } & \multirow[t]{2}{*}{ OS (\%) } & \multicolumn{2}{|c|}{$\begin{array}{c}\text { Number of } \\
\text { complications }\end{array}$} \\
\hline & & & & & & Skin-related & Other \\
\hline Aryus et al [10] & 32 & NS & NS & NS & NS & NS & NS \\
\hline Skinner et al [25] & 7 & NS & NS & NS & NS & 7 & 1 \\
\hline Gerlach et al [15] & 56 & NS & NS & $\begin{array}{c}\text { Median } 25(6-36) \\
\text { months tumour } \\
\text { free survival }\end{array}$ & $\begin{array}{l}19(2-64) \\
\text { months OS time }\end{array}$ & NS & NS \\
\hline Ho et al [16] & NS & 3 & $\begin{array}{l}23 \% \text { of } 30 \text { patients } \\
\text { had distant relapse }\end{array}$ & $68^{a}$ & NS & 7 & 6 \\
\hline Zinzindohoue et al [27] & 18 & NS & NS & NS & NS & 5 & 1 \\
\hline
\end{tabular}

NS, Not stated; pCR, Pathological complete response in breast; (), Pathological complete response in axillary nodes (pCRA); NCRT, Neo-adjuvant chemo-

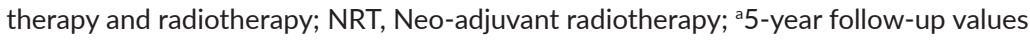

b10-year follow-up values

c15-year follow-up values

d25-year follow-up values

eBased upon imaging

${ }^{\mathrm{f}} \mathrm{Number}$ of patients free of disease at median follow-up

gNumber of patients alive at median follow-up

${ }^{\mathrm{h}}$ Calculated mean of OS from $\mathrm{pCR}$ and non-pCR groups

'As a proportion of 50 patients with upfront decision for mastectomy only

\section{Results of included studies}

The study by Semiglazov et al [23] was the only study which randomised patients due to undergo mastectomy to either neoadjuvant chemotherapy and radiotherapy (NCRT), or to NRT alone. They did not make any comparison with standard adjuvant RT. Two further cohort studies reported outcomes following NRT alone [12, 21]. The authors identified that the pCR rate was $35 \%$ and $28 \%$ in the NCRT and NRT groups, respectively. The study by Ishitobi et al [17] was the only study to use neo-adjuvant endocrine therapy with an aromatase inhibitor in patients undergoing breast-conserving surgery (BCS) and did not identify any cases of pCR. The remaining studies all administered NCRT with a pCR rate reported between 14\% and 42\% [9, 20]. Five studies $[8,9,13,21,27]$ evaluated $\mathrm{pCR}$ according to tumour receptor status (Table 3 ) and demonstrated greater pCR rates in oestrogen receptor (ER) negative patients.

DFS at 5 -years was reported as $81 \%$ versus $71.6 \%$ in the NCRT and NRT groups, respectively $(p<0.04)$ [23] and 10 -year DFS as $68 \%$ versus $67.3 \%$ in NCRT and adjuvant treatment groups [22] when directly compared in studies. The OS at 5-years in the NCRT versus NRT study [23] 
Table 3. Methodological characteristics and quality assessment of included studies.

(a) Cohort studies involving preoperative RT and/or CT

\begin{tabular}{|c|c|c|c|c|c|c|}
\hline Study & $\begin{array}{c}\text { Study } \\
\text { objectives }\end{array}$ & $\begin{array}{l}\text { Clear inclusion } \\
\text { criteria }\end{array}$ & $\begin{array}{c}\text { Standardised } \\
\text { treatment technique }\end{array}$ & $\begin{array}{c}\text { Standardised } \\
\text { histopathology assessment }\end{array}$ & $\begin{array}{l}\text { Patient follow-up } \\
\text { reported }\end{array}$ & $\begin{array}{l}\text { Withdrawals from } \\
\text { study reported }\end{array}$ \\
\hline Touboul et al [26] & Yes & Yes & Yes & Yes & Yes & Yes \\
\hline Colleoni et al [13] & Yes & Yes & Yes & NS & NS & NS \\
\hline Skinner et al [33] & Yes & Yes & Yes & NS & Yes & Yes \\
\hline Lerouge et al [18] & Yes & Yes & Yes & Yes & Yes & Yes \\
\hline Chakravarthy et al [34] & Yes & Yes & Yes & Yes & Yes & Yes \\
\hline Shanta et al [24] & Yes & Yes & Yes & NS & Yes & Yes \\
\hline Alvarado-Miranda et al [9] & Yes & Yes & Yes & Yes & Yes & Yes \\
\hline Adams et al [8] & Yes & Yes & Yes & Yes & Yes & Yes \\
\hline Roth et al [22] & Yes & Yes & Yes & Yes & NS & Yes \\
\hline Daveau et al [14] & Yes & Yes & Yes & NS & NS & Yes \\
\hline Bollet et al [11] & Yes & Yes & Yes & Yes & Yes & Yes \\
\hline Ishitobi et al [17] & Yes & Yes & Yes & Yes & NS & Yes \\
\hline Matuschek et al [19] & Yes & Yes & Yes & Yes & NS & Yes \\
\hline Nardone et al [20] & Yes & Yes & Yes & Yes & Yes & Yes \\
\hline Pazos et al [28] & Yes & Yes & Yes & NS & Yes & Yes \\
\hline
\end{tabular}

(b) Cohort studies involving preoperative RT only

\begin{tabular}{|c|c|c|c|c|c|c|}
\hline Study & $\begin{array}{c}\text { Study } \\
\text { objectives }\end{array}$ & $\begin{array}{c}\text { Clear inclusion } \\
\text { criteria }\end{array}$ & $\begin{array}{c}\text { Standardised treatment } \\
\text { technique }\end{array}$ & $\begin{array}{c}\text { Standardised histopathology } \\
\text { assessment }\end{array}$ & $\begin{array}{l}\text { Patient follow-up } \\
\text { reported }\end{array}$ & $\begin{array}{l}\text { Withdrawals from } \\
\text { study reported }\end{array}$ \\
\hline Calitchi et al [12] & Yes & Yes & Yes & No & Yes & Yes \\
\hline Riet et al [21] & Yes & Yes & Yes & Yes & Yes & Yes \\
\hline
\end{tabular}

(c) Cohort studies involving preoperative RT and/or CT with breast reconstruction

\begin{tabular}{|c|c|c|c|c|c|c|}
\hline Study & $\begin{array}{c}\text { Study } \\
\text { objectives }\end{array}$ & $\begin{array}{l}\text { Clear inclusion } \\
\text { criteria }\end{array}$ & $\begin{array}{l}\text { Standardised } \\
\text { treatment technique }\end{array}$ & $\begin{array}{c}\text { Standardised } \\
\text { histopathology assessment }\end{array}$ & $\begin{array}{l}\text { Patient follow-up } \\
\text { reported }\end{array}$ & $\begin{array}{l}\text { Withdrawals from } \\
\text { study reported }\end{array}$ \\
\hline Aryus et al [10] & Yes & Yes & Yes & Yes & Yes & Yes \\
\hline Skinner et al [25] & Yes & Yes & Yes & Yes & NS & Yes \\
\hline Gerlach et al [15] & Yes & Yes & Yes & Yes & NS & Yes \\
\hline Ho et al [16] & Yes & Yes & Yes & NS & Yes & Yes \\
\hline Zinzindohoue et al [27] & Yes & Yes & Yes & Yes & Yes & Yes \\
\hline
\end{tabular}

(d) Randomised control trials

\begin{tabular}{|c|c|c|c|c|c|c|}
\hline Study & $\begin{array}{c}\text { Power } \\
\text { analysis }\end{array}$ & $\begin{array}{c}\text { Adequate sequence } \\
\text { generation }\end{array}$ & $\begin{array}{c}\text { Allocation } \\
\text { concealment }\end{array}$ & $\begin{array}{c}\text { Blinding (participants and } \\
\text { personnel and all outcomes) }\end{array}$ & $\begin{array}{c}\text { Incomplete data } \\
\text { addressed }\end{array}$ & $\begin{array}{c}\text { Free of selective } \\
\text { reporting }\end{array}$ \\
$\begin{array}{c}\text { Free of } \\
\text { other bias }\end{array}$ \\
\hline Semiglazov et al [23] & No & Yes & Yes & NS & Yes & Yes \\
\hline
\end{tabular}

NS, Not stated 
Table 4. Outcome of included studies reporting data by tumour phenotype. (a) Pathological complete response reported by tumour phenotype

\begin{tabular}{|l|c|c|c|c|}
\hline \multicolumn{1}{|c|}{ Study } & \multicolumn{4}{c|}{ pCR (\%) } \\
\hline & ER+ & ER- & HER2+ & Triple negative \\
\hline Riet et al [21] & & & & 26 \\
\hline Zinzindohoue et al [27] & 44.5 & 55.5 & 11 & \\
\hline Colleoni et al [13] & 38 & 44 & & \\
\hline Alvarado-Miranda et al [9] & $54[45-63]$ & $81[74-88]$ & & \\
\hline Adams et al [8] & $52^{c}$ & $50^{c}$ & $32^{c}$ & \\
\hline
\end{tabular}

(b) Locoregional recurrence and distant DFS reported by tumour phenotype

\begin{tabular}{|c|c|c|c|c|c|c|c|c|}
\hline \multirow[t]{2}{*}{ Study } & \multicolumn{4}{|c|}{ Locoregional recurrence rate (\%) } & \multicolumn{4}{|c|}{ Distant DFS (\%) } \\
\hline & ER+ & ER- & Her2+ & Triple negative & ER+ & ER- & Her2+ & Triple negative \\
\hline Bollet et al [11] & $93^{\mathrm{a}}[85-100]$ & $80^{\mathrm{a}}[61-100]$ & $75^{\mathrm{a}}[50--100]$ & $91^{a}[83-100]$ & $88 a$ [78--98] & $69^{a}[49-96]$ & $75^{\mathrm{a}}[50-100]$ & $75^{\mathrm{a}}[54-100]$ \\
\hline Lerouge et al [18] & & & & & $69.9^{b}(+/-8)$ & $64.3^{b}(+/-11.8)$ & & \\
\hline After NRT alone & & & & & $68.4^{\mathrm{b}}(+/--10.7)$ & $51.6^{\mathrm{b}}(+/-14.5)$ & & \\
\hline $\begin{array}{l}\text { Alvarado-Miranda } \\
\text { et al [9] }\end{array}$ & & & & & $93^{a}(+/-3)$ & $83^{a}(+/-4)$ & & \\
\hline
\end{tabular}

a5-yearb10-yearclncludes complete and partial pathological response

was $86 \%$ and $78 \%$, respectively, and $69 \%$ versus $65 \%$ in the NCRT and adjuvant treatment groups [22]. When NCRT was not followed by definitive surgery, the 10-year DFS was $52 \%$ and $61 \%(p=0.73)$ and OS $77 \%$ and $79 \%$ for no surgery and surgery, respectively [14]. In the other studies with patients undergoing NRT alone, Riet et al [21] reported a pCR rate of $10 \%$ with $30 \%$ OS and DFS at 25 -year follow-up. Calitchi et al [12] reported a $47 \%$ and 55\% DFS and OS at 15-year follow-up.

In the cohort studies reporting 10-year follow-up after neo-adjuvant radiochemotherapy (NRCT), the DFS was reported between $52.6 \%$ and $68 \%$, with OS at the same time point being between 63\% and 69\% [18, 22, 24, 26]. Two further studies, which recorded 5-year DFS in NCRT cohort's reported figures between $61.4 \%$ and $76.9 \%$ and OS between $71.6 \%$ and $84.2 \%$ [8, 9]. A single study of $15-y e a r$ DFS in a NCRT cohort reported a figure of $47 \%$ and OS of $55 \%$ [12]. The study by Ishitobi et al [17] of neo-adjuvant endocrine therapy demonstrated 24 out of 25 patients alive and disease-free at a median of 18 months follow-up. Nardone and Pazos et al [20, 28] reported 19 of 21 and 18 out of 22 patients disease-free at median follow-up of 30 months. The authors also reported all 21 and 18 out of 22 patients alive at follow-up [20, 28].

The incidence of loco-regional and distant metastatic disease is shown in Table 4. The study with the longest median follow-up after preoperative NRT alone of 384 months showed an $8 \%$ local recurrence rate [21]. This was followed by 15 year follow-up of a NRT cohort which reported local recurrence and metastatic rates of $12 \%$ and $36 \%$, respectively [12]. Lerouge et al [18] reported a $9 \%$ local recurrence rate and $8.3 \%$ of metastatic cases after a 140 month median follow-up of NCRT. Bollet et al [11] reported a median follow-up of 84 months, with $12 \%$ and $22 \%$ local recurrences and metastatic cases, respectively.

Studies with follow-up of up to 60 months demonstrated lower rates of between $0.8 \%$ and $10 \%$ for local recurrence and $3.5 \%$ and $23 \%$ for cases of metastases [8, 9, 16, 17, 20, 25, 28]. The study by Daveau et al [14] demonstrated no significant difference in metastatic cases between NCRT followed by surgery or no surgery. Whilst this was replicated in the local recurrence rate, there was a trend towards better local control in the surgery groups (16.9\% versus $32 \%)$. 
Five studies reported the use of breast reconstruction in a total of 264 patients following NRCT and primary surgery [10, 15, 16, 25, 27]. Of these, 232 patients (87.8\%) underwent autologous reconstruction, and the remaining 32 patients' reconstructions involved prosthetic implants. All patients that received implants came from the same study [27], in which they were used to augment latissimus dorsi (LD) flaps. In those patients receiving autologous reconstruction, 87 had a transverse rectus abdominis (TRAM) flap, 176 had an LD flap and 1 patient had a combination of TRAM/LD flaps. The pCR in the breast reconstruction studies ranged from $21.7 \%$ to $58.2 \%$ [10, 27]. Follow-up was reported in two of these studies at median of between 24 and 42 months [16, 27]. Complications relating to breast reconstruction included cellulitis, partial flap necrosis and fat necrosis. Ho et al [16] reported donor site complications in $20 \%$ of patients and a single case of flap necrosis requiring debridement. The remaining studies all demonstrated skin complications, which settled with conservative management, including the study by Zinzindohoue et al [27]-that included 38.5\% of patients undergoing implant based reconstruction-reporting five cases of skin necrosis, which healed at 2 months with surgical revision and dressings.

Complications were mainly distributed between neutropenia and anaemia and skin changes (Table 4). The study by Alvarado-Miranda et al [9] reported radiation dermatitis in $22.4 \%$ of patients compared to only $7.7 \%$ in the study by Semiglazov et al [23]. There were no cases of neutropenic sepsis reported.

\section{Discussion}

NAC has become widely applied in the treatment of locally advanced breast cancer but the performance of NRT has not. This is in contrast to other malignancies in which it has become established as a standard of care, with improved OS [2]. The studies within this review demonstrate that the administration of NRT-in comparable doses to adjuvant RT-is well tolerated in breast surgical oncological procedures $[9,14,23]$ and when combined with breast reconstruction [27]. The combination of NCRT when directly compared against NRT alone demonstrated superior pCR rates, DFS and OS at 5 years-although only DFS reached statistical significance [23]. This would support the combined, enhanced tumouricidal effects of NCRT compared to NRT alone, which have already been demonstrated in rectal cancer [3]. These tumouricidal effects were not replicated with the application of neo-adjuvant endocrine therapy, where no cases of pCR were reported [17]. A pCR was significantly associated with hormone receptor negative compared to positive cancers on univariate analysis ( $p<0.002$ ) [9]. This is demonstrated by the increased rates of pCR-as would be expected-in those patients that are ER negative compared to positive (Table 4a). This supports the theory of chemosensitisation of certain cell lines by administration of concurrent RT, preventing the activation of pro-survival transcription factors and the MDR-1 gene [20]. This clearly reiterates the importance of molecular phenotype of tumours with respect to their hormone receptor and HER2 status in determining their likely response to neo-adjuvant therapy. From the poor pCR results of neo-adjuvant endocrine therapy combined with NRT, it is suggestive that there is a lack of a hormone sensitising effect by concurrent RT [17]. The Surveillance, Epidemiology, and End Results (SEER) database analysis of 250,195 women with early breast cancer who underwent NRT $(2,554)$ and adjuvant RT $(247,641)$ demonstrated that NRT resulted in a lower hazard ratio for a second primary tumour at any location among ER positive patients compared to adjuvant RT (HR 0.64,95\% Cl 0.55-0.75; $p<0.0001$ ) and in those undergoing NRT and mastectomy compared with those who received adjuvant RT (HR 0.48; 95\% Cl 0.26-0.87; $p=0.02$ ) [29]. Therefore, an important role of NRT combined with endocrine therapy may be to allow greater time for maximal tumour regression and avoidance of chemotherapy in a certain subset of patients, with improved outcomes.

The presence of a clearly visualised target pre-operatively for the administration of NRT is a clear advantage absent from adjuvant RT. This allows the application of whole breast RT with a boost to the precise target site or targeted RT to the tumour and surrounding normal tissue, without fear of missing the tumour bed. This strategy avoids the need to estimate the approximate position of the original tumour-as standardly directed by surgically placed titanium clips intra-operatively. This is of increasing clinical importance given the wider use of oncoplastic surgery, challenging subsequent adjuvant RT planning. The evaluation of NCRT for exclusive management without surgery demonstrated that DFS, OS, occurrence of metastatic and local disease were not significantly different [14]. These findings were in spite of only $41 \%$ of the non-surgical group undergoing a complete radiological response to NCRT [14]. This demonstrates the potential for NCRT to be performed as standalone therapy without surgery. The non-significant trend towards greater local relapse in the NCRT group was demonstrated on univariate analysis to be related to larger tumour size and younger age [14]. Therefore, careful selection of patients to avoid this subset of risk factors and consideration of molecular phenotyping could make this surgical-free treatment option feasible. 
The impact of timing of administration of RT in breast reconstruction varies between autologous and implant based. The Mastectomy Reconstruction Outcome Consortium [30] prospective cohort of patients undergoing autologous reconstruction demonstrated that no differences in complications were identified in patients receiving chest wall RT between delayed and immediate breast reconstruction. An insuranceclaims based series of nearly 5,000 patients [31] demonstrated that RT use in implant-based reconstruction is associated with an 11 times greater likelihood of failure compared with irradiated autologous reconstruction. However, with the former, delayed reconstruction after RT is associated with the highest probability of implant failure. In the five studies [10, 15, 16, 25, 27] using breast reconstruction, all involved autologous tissue and a single study autologous tissue with implants [27]. Whilst skin related complications were reported, no cases of flap failure or implant loss were reported and all cases settled with conservative management or minimal debridement. This would suggest that NRT can be applied to the reconstructive setting and avoid the problems of adjuvant RT with respect to its delayed administration should a surgical complication arise.

Within this review, it has been shown that when NCRT is compared to the standard of adjuvant treatment, no significant difference in DFS or OS was identified at 10 years [22]. The DFS, OS and recurrence rates of included studies [8, 9, 14, 22, 23] recording these outcomes are comparable to the gold standard of adjuvant treatment-as recorded at meta-analysis [32]. This is supported by the SEER database, which suggested that the ER positive patient population could experience significant benefits in reducing disease recurrence [29]. Clearly, there is heterogeneity amongst the studies regarding their NCRT protocols and the administration of adjuvant therapies as well as inclusion of only a single RCT-of NRT versus NRCT. This illustrates that currently RT is not being utilised within neo-adjuvant treatments. This review is inherently limited due to the lack of available evidence but highlights that the addition of NRT to NAC has a low side effect profile-including with breast reconstruction-and is oncologically safe.

\section{Conclusion}

The application of NRT in the treatment of breast cancer patients can streamline oncological treatment, provide chemosensitisation to enhance pCR prior to definitive surgery and provide treatment alternatives to ER positive patients who are less likely to respond to chemotherapy. Indeed, there is even potential that in a carefully selected subgroup of patients according to their histopathological and molecular features, the need for surgical intervention may be obviated. The potential benefits of NCRT (with or without biological agents) now warrant further exploration within prospective, RCTs to evaluate their potential benefits, in addition to that of NRT versus the standard of adjuvant RT.

\section{Conflicts of interest statement}

The authors have no disclosures to make concerning financial or personal relationships that could inappropriately influence their work.

\section{Funding declaration}

No funding was received for this study.

\section{References}

1. Bui DL and Yu JB (2015) Trends in adjuvant and neoadjuvant radiotherapy for cancer treatment from 1973 to 2011 Cancer J 21(3) 147-149 https://doi.org/10.1097/PPO.0000000000000114 PMID: 26049692

2. Colorectal Cancer Collaborative G (2001) Adjuvant radiotherapy for rectal cancer: a systematic overview of 8,507 patients from 22 randomised trials Lancet 358(9290) 1291-1304. https://doi.org/10.1016/S0140-6736(01)06409-1

3. Bosset JF, Calais G, and Mineur L, et al (2005) Enhanced tumorocidal effect of chemotherapy with preoperative radiotherapy for rectal cancer: preliminary results--EORTC $22921 \mathrm{~J}$ Clin Oncol 23(24) 5620-5627 https://doi.org/10.1200/JCO.2005.02.113 PMID: 16009958 
4. Gerard JP, Conroy T, and Bonnetain F, et al (2006) Preoperative radiotherapy with or without concurrent fluorouracil and leucovorin in T3-4 rectal cancers: results of FFCD 9203 J Clin Oncol 24(28) 4620-4625 https://doi.org/10.1200/JCO.2006.06.7629 PMID: 17008704

5. Bonner JA, Harari PM, and Giralt J, et al (2010) Radiotherapy plus cetuximab for locoregionally advanced head and neck cancer: 5-year survival data from a phase 3 randomised trial, and relation between cetuximab-induced rash and survival Lancet Oncol 11(1) 21-28 https://doi.org/10.1016/S1470-2045(09)70311-0

6. The Nordic Cochrane Centre CC (2008) Review Manager (RevMan) [Computer program] Version 5.0

7. von Elm E, Altman DG, and Egger M, et al (2007) The strengthening the reporting of observational studies in epidemiology (STROBE) statement: guidelines for reporting observational studies Lancet 370(9596) 1453-1457 https://doi.org/10.1016/S0140-6736(07)61602-X PMID: 18064739

8. Adams S, Chakravarthy AB, and Donach M, et al (2010) Preoperative concurrent paclitaxel-radiation in locally advanced breast cancer: pathologic response correlates with five-year overall survival Breast Cancer Res Treat 124(3) 723-732

9. Alvarado-Miranda A, Arrieta O, and Gamboa-Vignolle C, et al (2009) Concurrent chemo-radiotherapy following neoadjuvant chemotherapy in locally advanced breast cancer Radiation oncology 424 https://doi.org/10.1186/1748-717X-4-24 PMID: 19591689 PMCID: 2716349

10. Aryus B, Audretsch W, and Gogolin F, et al (2000) Remission rates following preoperative chemotherapy and radiation therapy in patients with breast cancer Strahlentherapie und Onkologie : Organ der Deutschen Rontgengesellschaft [et al] 176(9) 411-415 https://doi. org/10.1007/PL00002349

11. Bollet MA, Sigal-Zafrani B, and Gambotti L, et al (2006) Pathological response to preoperative concurrent chemo-radiotherapy for breast cancer: results of a phase II study Eur J Cancer 42(14) 2286-2295 https://doi.org/10.1016/j.ejca.2006.03.026 PMID: 16893641

12. Calitchi E, Kirova YM, and Otmezguine Y, et al (2001) Long-term results of neoadjuvant radiation therapy for breast cancer Int $J$ Cancer 96(4) 253-259 https://doi.org/10.1002/ijc.1024 PMID: 11474500

13. Colleoni M, Nole F, and Minchella I, et al (1998) Pre-operative chemotherapy and radiotherapy in breast cancer Eur J Cancer 34(5) 641-645 https://doi.org/10.1016/S0959-8049(97)10091-0 PMID: 9713267

14. Daveau C, Savignoni A, and Abrous-Anane S, et al (2011) Is radiotherapy an option for early breast cancers with complete clinical response after neoadjuvant chemotherapy? Int J Radiat Oncol Biol Phys 79(5) 1452-1459 https://doi.org/10.1016/j.jijrobp.2010.01.003

15. Gerlach B, Audretsch W, and Gogolin F, et al (2003) Remission rates in breast cancer treated with preoperative chemotherapy and radiotherapy Strahlentherapie und Onkologie : Organ der Deutschen Rontgengesellschaft [et al] 179(5) 306-311 https://doi.org/10.1007/ s00066-003-1019-y

16. Ho AL, Tyldesley S, and Macadam SA, et al (2012) Skin-sparing mastectomy and immediate autologous breast reconstruction in locally advanced breast cancer patients: a UBC perspective Ann Surg Oncol 19(3) 892-900 https://doi.org/10.1245/s10434-011-1989-4

17. Ishitobi M, Suzuki O, and Komoike Y, et al (2014) Phase II study of neoadjuvant anastrozole and concurrent radiotherapy for postmenopausal breast cancer patients Breast Cancer 21(5) 550-556 https://doi.org/10.1007/s12282-012-0426-2

18. Lerouge D, Touboul E, and Lefranc JP, et al (2004) Combined chemotherapy and preoperative irradiation for locally advanced noninflammatory breast cancer: updated results in a series of 120 patients Int J Radiat Oncol Biol Phys 59(4) 1062-1073 https://doi.org/10.1016/j. ijrobp.2003.12.034 PMID: 15234040

19. Matuschek C, Bolke E, and Roth SL, et al (2012) Long-term outcome after neoadjuvant radiochemotherapy in locally advanced noninflammatory breast cancer and predictive factors for a pathologic complete remission: results of a multivariate analysis Strahlentherapie und Onkologie : Organ der Deutschen Rontgengesellschaft [et al] 188(9) 777-781 https://doi.org/10.1007/s00066-012-0162-8

20. Nardone L, Diletto B, and De Santis MC, et al (2014) Primary systemic treatment and concomitant low dose radiotherapy for breast cancer: final results of a prospective phase II study Breast 23(5) 597-602 https://doi.org/10.1016/j.breast.2014.06.005 PMID: 24998453 
21. Riet FG, Fayard F, and Arriagada R, et al (2017) Preoperative radiotherapy in breast cancer patients: 32 years of follow-up Eur J Cancer 76 45-51 https://doi.org/10.1016/j.ejca.2017.01.022 PMID: 28267657

22. Roth SL, Audretsch W, and Bojar H, et al (2010) Retrospective study of neoadjuvant versus adjuvant radiochemotherapy in locally advanced noninflammatory breast cancer: survival advantage in cT2 category by neoadjuvant radiochemotherapy Strahlentherapie und Onkologie : Organ der Deutschen Rontgengesellschaft [et al] 186(6) 299-306 https://doi.org/10.1007/s00066-010-2143-0

23. Semiglazov VF, Topuzov EE, and Bavli JL, et al (1994) Primary (neoadjuvant) chemotherapy and radiotherapy compared with primary radiotherapy alone in stage Ilb-Illa breast cancer Ann Oncol 5(7) 591-595 https://doi.org/10.1093/oxfordjournals.annonc.a058929 PMID: 7993833

24. Shanta V, Swaminathan R, and Rama R, et al (2008) Retrospective analysis of locally advanced noninflammatory breast cancer from Chennai, South India, 1990-1999 Int J Radiat Oncol Biol Phys 70(1) 51-58. https://doi.org/10.1016/j.jirobp.2007.05.050

25. Skinner KA, Silberman H, and Florentine B, et al (2000) Preoperative paclitaxel and radiotherapy for locally advanced breast cancer: surgical aspects Ann Surg Oncol 7(2) 145-149 https://doi.org/10.1007/s10434-000-0145-3 PMID: 10761794

26. Touboul E, Lefranc JP, and Blondon J, et al (1997) Primary chemotherapy and preoperative irradiation for patients with stage II larger than $3 \mathrm{~cm}$ or locally advanced non-inflammatory breast cancer Radiother Oncol 42(3) 219-229 https://doi.org/10.1016/S01678140(97)01923-3 PMID: 9155070

27. Zinzindohoue C, Bertrand P, and Michel A, et al (2016) A prospective study on skin-sparing mastectomy for immediate breast reconstruction with latissimus dorsi flap after neoadjuvant chemotherapy and radiotherapy in invasive breast carcinoma Ann Surg Oncol 23(7) 2350-2356 https://doi.org/10.1245/s10434-016-5146-y PMID: 26957504

28. Pazos M, Corradini S, and Dian D, et al (2017) Neoadjuvant radiotherapy followed by mastectomy and immediate breast reconstruction: an alternative treatment option for locally advanced breast cancer Strahlentherapie und Onkologie: Organ der Deutschen Rontgengesellschaft [et al] 193(4) 324-331 https://doi.org/10.1007/s00066-017-1100-6

29. Poleszczuk J, Luddy K, and Chen L, et al (2017) Neoadjuvant radiotherapy of early-stage breast cancer and long-term disease-free survival Breast Cancer Res 19(1) 75 https://doi.org/10.1186/s13058-017-0870-1 PMID: 28666457 PMCID: 5493088

30. Billig J, Jagsi R, and Qi J, et al (2017) Should immediate autologous breast reconstruction be considered in women who require postmastectomy radiation therapy? A prospective analysis of outcomes Plast Reconstr Surg 139(6) 1279-1288 https://doi.org/10.1097/ PRS.0000000000003331 PMID: 28198770 PMCID: 5676536

31. Chetta MD, Aliu O, and Zhong L, et al (2017) Reconstruction of the irradiated breast: a national claims-based assessment of postoperative morbidity Plast Reconstr Surg 139(4) 783-792 https://doi.org/10.1097/PRS.0000000000003168 PMCID: 5373960

32. Early Breast Cancer Trialists' Collaborative G, Peto R, and Davies C, et al (2012) Comparisons between different polychemotherapy regimens for early breast cancer: meta-analyses of long-term outcome among 100,000 women in 123 randomised trials Lancet 379(9814) 432-444 https://doi.org/10.1016/S0140-6736(11)61625-5

33. Skinner KA, Dunnington G, and Silberman H, et al (1997) Preoperative 5-fluorouracil and radiation therapy for locally advanced breast cancer Am J Surg 174(6) 705-7; 707-8 https://doi.org/10.1016/s0002-9610(97)00198-0 PMID: 9409601

34. Chakravarthy AB, Kelley MC, and McLaren B, et al (2006) Neoadjuvant concurrent paclitaxel and radiation in stage II/III breast cancer Clin Cancer Res 12(5) 1570-6 https://doi.org/10.1158/1078-0432.CCR-05-2304 PMID: 16533783 